\title{
Hinchadas y barras de fútbol en la América Latina contemporánea: Hacia un análisis transnacional y una comparación en escala continental
}

\author{
Buarque de Hollanda, Bernardo \\ Pontifícia Universidad Católica de Rio de Janeiro, \\ Brasil bernardobuarque@gmail.com \\ Magazine, Roger \\ Universidad Iberoamericana, \\ México roger.magazine@uia.mx \\ Rodríguez Aguilar, Onésimo \\ Universidad de Costa Rica, Costa \\ Rica oneboticario@gmail.com \\ Cabrera, Nicolás \\ Universidad Nacional de San Martín - CONICET, \\ Argentina nico_cab@ hotmail.com
}

Cita sugerida: Buarque de Hollanda, B., Magazine, R., Rodríguez Aguilar, O. y Cabrera, N. (2018). Hinchadas y barras de fútbol en la América Latina contemporánea: Hacia un análisis transnacional y una comparación en escala continental. Cuestiones de Sociología, 18, e051. https://doi.org/10.24215/23468904e051 


\section{Hinchadas y barras de fútbol en la América Latina contemporánea: Hacia un análisis transnacional y una comparación en escala continental}

Football fans and supporters groups in contemporary Latin America: Towards a transnational analysis and a comparison on a continental scale

Bernardo Buarque de Hollanda

Pontifícia Universidad Católica de Rio de Janeiro, Brasil

bernardobuarque@gmail.com

Roger Magazine

Universidad Iberoamericana, México

roger.magazine@uia.mx

Onésimo Rodríguez Aguilar

Universidad de Costa Rica, Costa Rica

oneboticario@gmail.com

Nicolás Cabrera

Universidad Nacional de San Martín - CONICET,

Argentina

nico_cab@hotmail.com

\section{Resumen:}

Este artículo describe y analiza comparativamente las prácticas y representaciones asociadas a las barras, hinchas e hinchadas organizadas de cuatro países latinoamericanos: Argentina, Brasil, Costa Rica y México. Con base en elementos sincrónicos y diacrónicos, el objetivo es entender tanto las características compartidas como las especificidades de esas agrupaciones y sus modos de apoyo clubístico durante la segunda mitad del siglo XX y las primeras décadas del siglo XXI. El argumento propuesto sostiene que hay más semejanzas estructurales que diferencias puntuales en el universo latinoamericano examinado. Para demostrar este argumento, se eligieron tres variables principales para comparar: 1. La historia del surgimiento y de la formación de estos grupos en cada uno de los países elegidos; 2 . El modo de funcionamiento y organización contemporánea de esas entidades respecto a la distribución interna de poder, a la adquisición de prestigio y a las dificultades de mantenimiento del comando de los directivos, amenazados por el crecimiento cuantitativo y territorial de las hinchadas en los últimos decenios; 3. La comprensión de los discursos y de los datos cuantitativos relacionados con violencia entre hinchadas, tema controvertido del debate público en todos los países investigados, con un proceso de estigmatización que se alterna con formas jurídicas de criminalización de determinados grupos, en ciertos casos. Se concluye con el énfasis en la importancia de la continuidad de procedimientos analíticos comparativos, capaces de extrapolar, cuando no de cuestionar, los límites del enfoque centrado tan solo en casos nacionales. Se entiende que esta escala limitada impide una comprensión más precisa de aspectos transnacionales de los estilos y prácticas de los seguidores del fútbol profesional, en su fase actual de espectacularización y mediatización.

Palabras claVe: Hinchadas, Barras, América Latina, Historia, Estructura organizacional jerárquica, Violencia.

\section{ABstract:}

This article describes and analyzes, from a comparative perspective, the practices and representations associated with football fans and supporters' groups in four Latin American countries: Argentina, Brazil, Costa Rica and Mexico. Based on both synchronic and diachronic examination of the data, the objective is to understand the shared characteristics and the specificities of these groups and their support of club teams during the second half of the 20th century and the first decades of the 21 st. The argument proposes that in the Latin American cases examined there are more similarities than differences. To demonstrate this argument, three main variables were chosen for comparison: 1 . The history of the emergence and formation of these groups in each of the selected countries; 2 . The groups' contemporary workings and organization, including the internal distribution of power, the acquisition of prestige, and the difficulties leaders face maintaining command as the groups have grown in membership and territorial reach in recent decades; 3 . The analysis of discourses and quantitative data related to violence among supporters, a controversial issue of public debate in all the countries under consideration, revealing processes of stigmatization or, in some cases, legal forms of 
criminalization of certain groups. It concludes with emphasis on the need for further comparative analysis, capable of extrapolating, if not questioning, an approach limited to single national cases. Such a limited approach precludes an accurate understanding of transnational aspects of supporters' styles and practices as they follow professional football, in its current phase of spectatorization and mediatization.

KEYWORDS: Football fans, Supporters' groups, Latin America, History, Hierarchical organizational structure, Violence.

\section{INTRODUCCIÓN}

El presente artículo plantea una reflexión comparada sobre el fenómeno de las hinchadas organizadas en el fútbol profesional contemporáneo, tal como se manifiesta y se desarrolla en cuatro países de América Latina: Argentina, Brasil, Costa Rica y México. El texto es fruto de un esfuerzo colectivo de especialistas de la temática en reflejar de manera conjunta las semejanzas y diferencias existentes en las prácticas y en los valores desarrollados por esos agrupamientos de hinchadas, dentro y fuera de los estadios, durante los últimos años.

En ese sentido, para abordar la realidad de cuatro países latinoamericanos en conjunto, se eligieron tres ejes principales capaces de presentar una comparación transversal. El primer eje trata la dimensión temporal, con el fin de observar cómo se dio históricamente el proceso de surgimiento, de formación y de consolidación de asociaciones de hinchas, dedicadas a apoyar a equipos de fútbol profesionales en América Latina, a lo largo del siglo XX y principios del siglo XXI.

El segundo eje desarrollado en este artículo tiene un sentido menos histórico y más antropológico. Sin dejar de tener en cuenta la dinámica de cambios, esta sección trata de retener aspectos intrínsecos de la morfología social y política de los subgrupos, sus principios de antigüedad, prestigio y estatus, tal como se estructuran en la actualidad, con hincapié en la estructuración interna de cada hinchada. Se busca entender cómo se configuran las relaciones jerárquicas de poder, los valores morales predominantes y las divisiones sociales que subyacen a su estructura organizacional.

El tercer y último eje atañe a la temática de la violencia. Tomando a la sociología de Elias como referencia y a su tesis sobre la progresiva internalización del rechazo a la violencia en los deportes modernos, se verificó un proceso propio de los últimos años: el desplazamiento espacio-temporal de los conflictos entre hinchadas. $\mathrm{Si}$ anteriormente las peleas y disturbios se desarrollaban principalmente en los estadios de fútbol, ahora esas violencias han migrado a otros escenarios como los alrededores de las plazas deportivas, los momentos de traslado de los hinchas o los barrios donde viven.

\section{EJE UNO: LA DIMENSIÓN DIACRÓNICA}

En un sentido general, Argentina, Brasil, Costa Rica y México pasaron por etapas económicas-políticas similares durante el curso del siglo XX: la consolidación del Estado nación y su identidad durante las primeras décadas del siglo; luego un periodo de crecimiento económico y urbanización bajo políticas de sustitución de importaciones y un Estado corporativista fuerte en las décadas medianas; y, finalmente, un periodo de neoliberalismo y supuesta democratización.

Sin embargo, el fútbol como deporte espectáculo se ha cruzado de diferentes maneras con estas etapas en los diferentes países. En Brasil, y particularmente en Argentina, la identidad nacional que emergió al principio del siglo pasado estuvo fuertemente conectada a la vida moderna-urbana y más específicamente al fútbol y los estilos de juego nacionales que fueron contrastados con los de los poderes europeos, en particular con Inglaterra. En contraste, en México y Costa Rica, esta identidad emergente estuvo más conectada con el mundo rural, representada, por ejemplo, a través de los mariachis, el tequila y el Día de Muertos en el caso de México. Aunque el fútbol profesional no estuvo ausente durante la primera mitad del siglo XX en estos dos países, no ocupaba el mismo lugar privilegiado que en el imaginario nacional de Argentina y Brasil y por lo tanto no jugó un papel tan determinante en la formación del Estado y de la sociedad civil en este periodo. 
Si en Costa Rica y México no hay referencias a grupos organizados de hinchas hasta la década de 1980, en Argentina hay referencias a "barras" en los diarios desde los años 1920 (Frydenberg, 2011). Incluso, encontramos en el diario Crítica el primer uso del calificativo "brava" en 1925, cuando habla de un grupo de "energúmenos que solamente van a los fieldscon el objeto de poner de manifiesto sus bajos instintos" (Frydenberg, 2011, p. 225). En Brasil, las primeras "torcidas organizadas" o "torcidas uniformizadas", como se conocieron originalmente en Río de Janeiro, surgen a principios de los años 1940.

Como en el caso de Argentina, estos grupos brasileños son extensiones de los clubes deportivos -elementos significativos de la emergente sociedad civil y de la adopción del profesionalismo en el fútbol-, y están organizados jerárquicamente bajo el mando de un "jefe" que representa la autoridad del club. En la ciudad de São Paulo, según el periodista Alberto Helena Jr. (Silva, 1996), los grupos fueron inspirados en las audiencias de deportes universitarios norteamericanos con adornos y camisas de colores. La idea fue traída a la capital paulista por estudiantes de derecho y socios de clubes de élite que viajaban a Estados Unidos e importaban esa novedad para animar los partidos de clubes como el São Paulo y el Palmeiras.

En Río, el modelo no reflejó aspiraciones a la modernidad, sino una práctica cultural local instituida en la década de 1930: el desfile de las escolas de samba. Las gradas comenzaron a tener su propio "juego" basado en los criterios de estas escuelas: animación, música, ritmo, etc. Los aficionados organizados pasaron a usar la camiseta con los colores del equipo. Se produce una especie de "carnavalización de las gradas" y, como parte del proceso de comercialización del espectáculo, el espectador deja de tener una postura meramente pasiva. El nuevo papel de la hinchada organizada es el de animar al equipo y a los otros aficionados.

Si las barras y torcidas organizadas reprodujeron el orden jerárquico del Estado corporativista, también jugarán un papel en la resistencia en contra de las dictaduras de este periodo. En Argentina, con el derrocamiento del peronismo en $1955^{1}$ y su posterior proscripción, el país entra en un largo período de clausura de los principales canales democráticos-institucionales de participación, el cual genera la necesidad de encontrar nuevas formas de asociación y expresión. Al mismo tiempo, una forma nueva de "ser joven", vinculada a la acción y la resistencia, surge no sólo en Argentina, sino en varias partes del mundo.

Específicamente en Argentina, el telón de fondo es el paso de una cultura política de la resistencia cultivada durante la década de 1950 - a una cultura política de la confrontación. La acción directa, colectiva y organizada, con el uso de la violencia física como repertorio de acción legítimo gana terreno como experiencia propia del ser joven. El fútbol, que ya ocupaba bajo el peronismo un papel importante de inclusión y expresión para una gran parte de los sectores populares recientemente incluidos en el proyecto de modernidad nacional, fue el contexto donde los jóvenes de sectores populares encontraron un espacio de fuga y de acción colectiva para afirmar una forma de ser de acuerdo con los retos y el clima social-político de su época.

En Brasil ocurre una transformación similar. En los años 1960, el principio de unidad -un club, una hinchada, un jefe- es cuestionado. Surgen las torcidas jóvenes, formadas por nuevas generaciones que protestan contra el jefe de la hinchada y contra los dirigentes de los clubes. Las nuevas hinchadas organizadas rechazan la idea de que su función exclusiva es el apoyo al equipo. El abucheo y la protesta sistemática contra la dirección del club pasan a ser formas de actuación legítimas. La competencia entre los grupos de aficionados de un mismo equipo se basa en una oposición entre las antiguas y las nuevas torcidas. Durante la década de 1970, decenas de microgrupos surgen en las gradas de los estadios brasileños. Es preciso notar que estas disidencias aparecen dentro del contexto nacional de la dictadura militar y de un nuevo proceso de profesionalización del deporte donde los clubes se agigantan en términos de estructura y finanzas. Además, estos cambios entre las hinchadas organizadas ocurren en medio de un cuadro internacional de revueltas populares de cambio generacional de valores y de contestación estudiantil.

Los jóvenes en México y Costa Rica también participaron en esta cultura global de protesta; no obstante, lo hicieron fuera del contexto del fútbol. Mientras en Argentina y Brasil los años 50 y 60 vieron el surgimiento de grupos de hinchadas organizadas con un papel político significativo, en México y Costa Rica el fútbol apenas se estaba convirtiendo en un espectáculo de masas. En México, esta transformación fue impulsada por la 
emergente industria televisiva. En 1959, el hijo del dueño del corporativo Televisa, Emilio Azcárraga Milmo, compró al Club América como parte de una estrategia de crear una rivalidad con el popular club Chivas de Guadalajara y así construir una nueva audiencia televisiva masiva (Varela Hernández, 2012). Azcárraga también jugó un papel importante en la promoción de México como sede para los mundiales de 1970 y 1986 con el fin de atraer más televidentes a este deporte.

En la década de 1980 surgieron los primeros grupos de hinchadas organizadas en los estadios de fútbol en México. En Costa Rica, aparecieron una década después. En el caso de México, estos grupos, formados por entre 10 y 200 integrantes, eran conocidos como "porras", un nombre derivado de los grupos de estudiantes que alentaban a los equipos de fútbol americano. Su forma de apoyar al equipo consistía en gritar en conjunto vítores (conocidos como "porras" en México) sencillos y repetitivos en momentos claves del partido. Estos grupos generalmente estaban ligados a la directiva del equipo, o al menos no se oponían a ella. Se podría decir que con su lealtad no sólo al equipo, sino a su directiva y su posición acrítica, los aficionados replicaban la relación de este momento histórico entre la mayoría de las organizaciones de la sociedad civil y el Estado corporativista.

Con la instauración de políticas neoliberales y el debilitamiento del Estado corporativista en los años 1990 en estos dos países, se habían creado las condiciones para el surgimiento de barras. La eliminación de políticas de sustitución de importaciones y la apertura a mercados globales significó que los aficionados conocieron por la televisión de cable la forma de apoyar de los hinchas de Europa y Sudamérica: grupos grandes de jóvenes brincando y cantando al unísono de manera apasionada. Muchos jóvenes costarricenses y mexicanos se fascinaron por esta manifestación de una cultura juvenil en los estadios.

Estas formas de apoyar también llamaron la atención de algunas directivas de los equipos quienes vieron en estas prácticas una forma de aumentar el espectáculo y sus ganancias. Los dirigentes del Deportivo Saprissa, club costarricense, son los primeros en aprovechar esta oportunidad. En 1995 traen a integrantes de "Los Cruzados”, barra organizada de la Universidad Católica de Chile, para que estos inicien el proyecto de conjuntar a un grupo de personas que den aliento al club, creándose así la "Ultra Morada” (Rodríguez, 2006 y 2014b). El siguiente año, la directiva del Pachuca invitó a un costarricense, integrante de la Ultra Morada, para crear y dirigir a un grupo de apoyo entre los aficionados de este club mexicano, el cual recibiría el nombre de la "Ultra Tuza".

En general, las barras en Costa Rica y México fueron creaciones de las hinchadas y no de las directivas. El debilitamiento del Estado corporativista creó un vacío social que los jóvenes tuvieron la oportunidad de llenar con nuevas organizaciones y prácticas de su propia creación y elección (Magazine, 2008). Los jóvenes mexicanos, cansados de la falta de libertad bajo la jerarquía corporativista-clientelar de las porras y de la sociedad en general, reconocieron en las nuevas formas de apoyar una manera de expresar más libremente su pasión y amor por el juego y el club. Criticaron a las directivas de los equipos y las cadenas de televisión por su anticuado estilo clientelar. Algunos de los nombres de las autodenominadas "barras" reflejan esta oposición juvenil al establecimiento: "La Rebel”, "Libres y Lokos", "La Irreverente”. En los primeros años del nuevo milenio, todos los equipos de primera división de estos dos países ya contaban con una o más barras, las más grandes con más de 5 mil integrantes.

En Argentina y Brasil, las reformas neoliberales y la reapertura democrática también coincidieron con cambios importantes entre las hinchadas organizadas. Desde la década de 1980, en Argentina se da un aumento exponencial de heridos y muertos en el marco de lo que podríamos llamar conflictos clásicos: enfrentamientos entre barras de diferentes equipos y/o contra la policía; combates cuerpo a cuerpo donde progresivamente se hace uso de armas blancas y de fuego; dentro del estadio o alrededor de ellos, y durante los días de partido como principal referencia temporal. En Brasil en los años 80, en una coyuntura económicasocial de aumento de la violencia urbana y de criminalidad, las torcidas jóvenes crecieron en número de adeptos de una manera extraordinaria. Si hasta entonces sus integrantes tenían un perfil estudiantil, a partir de este momento tanto los líderes como la base de los componentes son estereotipados, según los medios de 
comunicación, como jóvenes pobres, desfavorecidos, provenientes de la periferia y las favelas que achacan a los clubes, insuflan actos de violencia e instituyen riñas mortales con otros grupos.

\section{EJE DOS: PODER, ORGANIZACIÓN Y ESTRUCTURA}

El poder y la organización dentro de las barras en Costa Rica, como en Argentina, Brasil y México, ha sido cambiante a lo largo del tiempo. Rodríguez (2006, 2014a y 2014b) expone, para el caso de una barra costarricense (durante la primera década del siglo XXI), una estructura basada en la existencia de varios líderes: un líder general, con varios depositarios de ese poder que fungían como colaboradores inmediatos (como ha sucedido en algún momento con algunas barras mexicanas, brasileñas y argentinas); estos tenían, sin duda, una cuota de mando importante, eran considerados como personas influyentes dentro de la agrupación, claro está, sin la trascendencia del líder general.

Después de estos colaboradores inmediatos, estaban los líderes de peñas. Eran jóvenes que encabezaban sus respectivas subagrupaciones, sin llegar a ostentar la importancia de los personajes anteriores. Finalmente, estaban los Ultras "razos", integrantes generales de la barra que se suman, regularmente, a alguna de las peñas (nombradas según los barrios de procedencia). Una de las razones por la cual los líderes ostentaban esa posición se debe a la posesión del "aguante": un conjunto de códigos masculinizados en donde se debe demostrar valor, fuerza y apoyo incondicional al club en las actividades de la barra (alentar al equipo, confrontaciones, peleas, organización, etcétera), sin evidenciar temor, sino más bien, arrojo y osadía ${ }^{2}$. En Costa Rica y México, el uso del término aguante, en el contexto de las barras, es resultado de la difusión del vocabulario barrista argentino. Sin embargo, el "aguante" también ha sido resignificado en estos países. Por ejemplo, esta condición temeraria no llega, usualmente, al enfrentamiento físico, el cual es muchas veces evitado por los barristas; entonces, el aguante tiene que ver, fundamentalmente, con apoyar al club (los jugadores) antes, en el transcurso y después del encuentro futbolístico. Ahora bien, el líder no solo debía poseer aguante, sino otro conjunto de destrezas, como en el caso argentino, relacionadas con la inteligencia, con un conocimiento que solo se obtiene estando en la barra, a través de la trayectoria; los jefes no eran neófitos, al contrario, eran personas con una larga historia dentro de la agrupación.

Actualmente, las barras en Costa Rica se organizan de forma diferente. La Ultra, según Rodríguez (2018), se ha desfragmentado (como ha sucedido en algunas barras argentinas y mexicanas). La unidad de antaño (organizada en un complejo estructural de mando) hoy no es tan visible; esto quizás como respuesta al ataque ejercido desde diversos actores sociales, fundamentalmente mediáticos, institucionales y dirigenciales y, claro está, a las luchas internas en la agrupación.

Hay una modalidad de mando central, pero a diferencia del modelo anterior, no es tan unificadora: se encarga de organizar a la barra y el conjunto de actividades que realizan (relacionadas con el performance estructurado del aliento ${ }^{3}$ ), pero no desarrolla un poder hegemónico como se hiciera en la década anterior, fundamentalmente, porque no puede: la misma lógica organizativa construida por las barras para poder alentar sin ser detectados e inhibidos por los controles policiales es la que ha propiciado que no se pueda percibir un mando superior y total como si lo fuera evidente hace algunos años.

La desfragmentación de la barra (por este pánico moral socialmente reproducido y la censura relacionada a él) ha sido el mecanismo ideado para poder subsistir como hinchada. El no poder manifestar abiertamente su identidad de barristas, viajar por separado, ocultar su filiación para poder ingresar a los escenarios, emplear un "perfil bajo" (a diferencia de las manifestaciones apoteósicas de antaño) han propiciado este modelo de organización que, si bien los ha hecho subsistir, trae como corolario pérdida de unidad.

Para el caso de las barras mexicanas, ciertos valores relacionados con la libertad, igualdad y rebeldía hacen fluir sentimientos de amor y pasión por el equipo (relacionados también con el "aguante"), lo cual ha influido en la estructura organizacional de las agrupaciones, en donde se divisa mayor unidad, a diferencia de la actualidad de las barras costarricenses. Por ejemplo, la Rebel de los Pumas de la UNAM (Universidad 
Nacional Autónoma de México), se formó con la propuesta de no tener líderes para evitar su cooptación por parte de las autoridades y para permitir la libre expresión del amor por el equipo dentro del grupo. Sin embargo, en la Rebel como en las demás barras, han surgido líderes y una organización jerárquica que contradice estos valores.

Estas jerarquías parecen haber surgido por dos razones principales. Primero, por cuestiones prácticas: con el rápido crecimiento de los grupos para incluir cientos y hasta miles de integrantes, fue necesario tener líderes para coordinar las acciones del grupo dentro y fuera del estadio. Segundo, y en concierto con la primera razón, algunos líderes surgieron por sus propias aspiraciones al poder. Con esto nos referimos a poder dentro de la misma barra, puesto que el liderazgo de las barras en México no ha sido un camino para alcanzar poder en otros sentidos, aunque sí puede implicar ganancias económicas suficientes para poder vivir de ellas. Es notable que las jerarquías y las ideologías de igualdad coexisten dentro de las barras.

Las barras mexicanas tienen uno o más líderes quienes organizan las actividades del grupo y vigilan el comportamiento de los integrantes. También son los que tienen contacto con la directiva del club - recibiendo y distribuyendo boletos de cortesía- y con las autoridades como la policía. Estos líderes generalmente son reconocidos por su aguante, pero para llegar a ser líder y mantener la posición también tienen que ser socialmente inteligentes y carismáticos (como se ha mencionado para los casos costarricense y argentino). Los líderes no son los más jóvenes en las barras pero tampoco son de otra generación, como en el caso de las barras argentinas; cuentan con el apoyo de algunos integrantes, a veces conocidos colectivamente como "la línea", que tienen relaciones cercanas y de confianza con ellos y que se encargan de actividades como las finanzas del grupo (frecuentemente una mujer hace esto), la organización de la banda musical, o la defensa física de los líderes y del grupo en general.

Por otro lado, las barras argentinas, al igual que hemos visto en Costa Rica y México, tienen estructuras organizativas complejas, dinámicas y heterogéneas, con algunas cercanías con sus homólogas centroamericanas y norteamericanas, pero también, con varias diferencias. En Argentina no existe un único modelo de barra. Hay diferencias según el tiempo y el espacio en el que nos situemos. Entre las primeras barras nacidas durante la década del sesenta y las actuales se observan importantes discontinuidades. Lo mismo podemos decir hoy entre una barra de un club "grande" de Buenos Aires y otra de un equipo de menores recursos de alguna provincia del interior. Sus lógicas de organización y funcionamiento dependen de una gran variedad de factores que deben analizarse partiendo de una especificidad irreductible de cada caso. Sin embargo, podemos hablar de una matriz organizativa que presenta ciertas recursividades que nos permiten diagramar un esquema general.

Las barras argentinas son colectivos fuertemente organizados en torno a una estructura piramidal de jerarquías, rangos, asimetrías y roles bien definidos a partir de una distribución desigual de los recursos grupalmente valorados y de una aceitada división de trabajo interna. Lejos de representar organizaciones monolíticas en su interior, en las barras conviven varios principios de diferenciación y jerarquización. A modo general, podemos decir que encontramos importantes coincidencias entre las barras argentinas en relación al siguiente organigrama:

A) Las barras tienen una organización piramidal. En la cima siempre hay una primera línea que está constituida por el/los capos o referentes (el liderazgo mayoritariamente es unipersonal pero a veces la conducción se puede distribuir entre dos o tres personas) y su círculo más íntimo o de confianza. En este grupo, como en todo espacio de privilegio, se da una relación inversamente proporcional entre su peso cuantitativo y el cualitativo. Estamos hablando de pocos sujetos - puede oscilar entre 5 y 20 personas aproximadamente- que toman la mayoría de las decisiones del colectivo. Mayoritariamente estas personas poseen larga trayectoria en la barra, buena relación con el/los capos -ya sea en términos afectivos o instrumentales- y gran reconocimiento grupal. En algunos casos el estatus se debe a relaciones de parentesco: el hermano de, el hijo de, el primo de. La cúspide de la pirámide implica una capacidad de negociación, obtención y distribución de recursos - tanto materiales como simbólicos- que se traduce, en varios casos, en 
una doble movilidad social ascendente: por un lado, al interior de la jerarquía de la hinchada y por el otro, en la estratificación del espacio social tomado como totalidad.

B) Luego encontramos al grueso de los miembros de la barra. Ellos representan la mayoría cuantitativa y pueden ser identificados nativamente como los pibes, la banda, la tropa, entre otros. Al interior de dicho grupo también coexisten criterios clasificatorios a partir de pertenencias a distintas facciones o subgrupos que se identifican por procedencias barriales (como en México y Costa Rica), espacios ubicados en la tribuna y lealtades a distintos referentes que están vinculados de una u otra forma al/los jefes máximos de la hinchada. Todos estos subgrupos se referencian con alguien de la primera línea. Este rango de la barra se caracteriza por ser la principal fuente de "mano de obra" de las actividades: producción, custodia, transporte y ubicación de los bombos, banderas y telones, organización de viajes, fuerza de choque para las peleas, entre otros. Generalmente entre la primera línea y la banda no solo hay diferencias de jerarquía sino también de edad, mientras que en los primeros la amplitud etaria está entre los 35 y 50 años, en los segundos encontramos jóvenes de 16 a 30 años. La composición intergeneracional es una marca distintiva de las barras argentinas que las diferencia, por ejemplo, de las torcidas organizadas brasileras y las barras mexicanas o costarricenses de fuerte identificación juvenil.

Hasta aquí tenemos lo que podemos llamar "núcleo duro", es decir, una cantidad de miembros estables, sistemáticos, comprometidos y fuertemente cohesionados - lo cual no significa anular el conflicto y la violencia como pauta de interacción entre ellos- que cotidianamente producen y reproducen la identidad colectiva de la hinchada a la cual se adscriben.

C) Por último, encontramos un tercer grupo de sujetos que se encuentran en una posición un tanto ambivalente en relación a la barra, ya que si bien no siempre son considerados por el "núcleo duro" o por ellos mismos como miembros, cumplen una doble función indispensable para la producción y reproducción de una barra: habitualmente participan de algunos rituales constitutivos del colectivo como reunirse en los lugares propios de la hinchada, viajar en sus colectivos, comprar los carnets de la hinchada, tocar los bombos o vientos, trasportar los telones, portar las banderas de mano e inclusive participar de los enfrentamientos violentos. Además, en muchas trayectorias esta posición se convierte en una primera aproximación a la hinchada a la que posteriormente pueden -o no- ingresar. En este grupo predomina una composición etaria de adolescentes y jóvenes.

En el caso brasileño, en los últimos años, se observa una nueva tendencia del Estado y de los medios de comunicación de masas en el enfoque de la violencia en los estadios de fútbol. Los medios de comunicación y los órganos estatales responsables han vuelto a invertir en la reinstitucionalización de las torcidas organizadas. La finalidad es la reincorporación de las hinchadas al proyecto de espectacularización del deporte y a los intereses comercial-pedagógicos del mercado. En vez de la tradicional estrategia de estigmatización, el canal que controla la transmisión del campeonato - perteneciente a la Red o Globo, una poderosa red de comunicación en Brasil- cambió su forma de abordaje. Dicha trasmisión ha estimuladola aparición de nuevas hinchadas conocidas bajo el nombre de "Legión Tricolor", "Locos por el Botafogo", "Urubuzada" y "Guerreros del Almirante".

La inversión de ciertos principios de las Torcidas Jóvenes -los nuevos grupos no admiten los abucheos, no hacen autoexaltación del nombre de la propia hinchada y no ofenden a los grupos adversarios- viene acompañada de un perfil social distinto de sus integrantes. Algunos de los creadores de estas torcidas tienen su origen en la clase media y son jóvenes asociados a los clubes que buscaron hacer un contrapeso al poder hegemónico de las antiguas torcidas. Inspirado en cánticos y formas de alentar de las torcidas argentinas, este nuevo movimiento brasilero, hasta cierto punto sorprendente, ha intentado competir con la hegemonía y el paradigma de violencia que históricamente caracterizó a las Torcidas Jóvenes.

Aunque todavía no hay estudios más profundos, es posible afirmar que el fenómeno de estas nuevas hinchadas nació en el estado Rio Grande do Sul y se extendió a todo el país. Una de sus novedades performativas, por ejemplo, es la "avalancha", un fenómeno en el que, durante la conmemoración de un gol, 
una masa compacta de aficionados corre hacia el alambrado que divide el campo de las gradas. Se comprime de una forma tal que en su desplazamiento produce un gran efecto televisual.

No se sabe aún si ese nuevo modelo, que se liga también a los orígenes y a la retórica de las hinchadas de los años 1940 y 1970, superará el modelo de las Torcidas Jóvenes. Se sabe, sin embargo, que ellas tienen el apoyo de los medios de comunicación, dentro de un proyecto pedagógico y de un interés mercantil que requiere una remodelación de la infraestructura de los estadios. En Brasil, la preparación para la Copa del Mundo de 2014 fue una ocasión considerada propicia por los gestores del fútbol para favorecer la formación de un nuevo público aficionado basado en el modelo del hincha consumidor.

\section{EJE TRES: LAS FORMAS DE VIOLENCIA}

La violencia es una dimensión fundamental para comprender a los grupos de espectadores organizados en torno a un equipo de fútbol. Más allá de cierto pánico moral (Hall, et al., 1978) reinante, es innegable que los enfrentamientos protagonizados por las barras o torcidas organizadas son experiencias constitutivas de estos colectivos. Ahora bien, afirmar lo anterior no habilita la homogeneización. La violencia entre los casos estudiados es tan heterogénea como dinámica, de allí la necesidad de trazar variantes de una constante.

En la Argentina se registran 322 víctimas fatales vinculadas a contextos futbolísticos. El primer homicidio en un estadio argentino sucede el 21 de octubre de 1922. Aunque la prensa gráfica ya habla de algunas "barras" aisladas en aquella época, será recién entre los cincuenta y los sesenta cuando ellas aparezcan con fuerza en la escena nacional. Lo que estamos tratando de decir es que, en el fútbol argentino, las muertes, las peleas y las armas preceden a las barras en tanto fenómeno institucionalizado. Sin embargo, queda claro que, a partir de la consolidación de estos grupos, la violencia se incrementa. Será con la reapertura democrática, a mediados de los ochenta, cuando aumenten exponencialmente los enfrentamientos que tienen como protagonistas a barras de diferentes equipos peleando entre sí o contra la policía. Durante la década de los noventa la violencia dentro de los estadios tiene su momento más crítico, lo que lleva a que se instale definitivamente una mirada estigmatizante y criminalizada sobre las barras argentinas.

Desde los últimos años de la primera década del siglo XXI hasta hoy, la violencia en el fútbol argentino está marcada por una aparente paradoja: hay estadios relativamente pacificados y al mismo tiempo un incremento exponencial de las víctimas fatales (Cabrera, 2018). Parte de lo ocurrido se explica por un desplazamiento espacio-temporal de los enfrentamientos. Los conflictos clásicos están dando paso a lo que podríamos llamar una privatización de la violencia (Elias, 1993). Esto significa que las peleas ya no tienen cabida en el escenario público por excelencia del fútbol: los estadios durante los días de partido.

Ahora las riñas se desenvuelven principalmente "detrás de bastidores" (Elias, 1993, p. 164): bares, plazas, bailes, recitales, barrios o clubes escenifican postales donde se mata y se muere en nombre de la pasión. Y no necesariamente durante los días de partido. Además, este desplazamiento espacio-temporal coincidió con una mutación de los protagonistas de los enfrentamientos: actualmente las peleas son mayoritariamente entre barras del mismo equipo. Este último cambio está directamente relacionado con la prohibición del público visitante que existe en la Argentina desde el 2007 para las categorías de ascenso y desde del 2013 en la primera división. Sabemos que en el caso argentino la identidad futbolística necesita de un enemigo como alteridad. Cuando ese "otro" dejó de estar al frente, se lo buscó a los costados. La consecuencia es tan sencilla como predecible, la violencia se desató entre hinchas del mismo equipo.

El caso brasilero tiene algunos paralelismos interesantes con el argentino. Desde la década del 1960, con la aparición de las torcidas organizadas jóvenes, la violencia se incrementa. Pero será en los noventa cuando el fenómeno impacta profundamente en la opinión pública. En un partido decisivo entre São Paulo y Palmeiras, transmitido por la televisión, las dos torcidas organizadas -Mancha Verde e Independente-invaden el campo y luchan con piedras y palos. El saldo final es un muerto y una centena de heridos. La estigmatización de las torcidas organizadas crece vertiginosamente. Así, estos colectivos quedan a mitad de camino entre 
una institucionalización en la vía pública con personería jurídica reconocida y una marginalización y estigmatización social.

Entre los noventa y el comienzo del milenio, la condena social a las torcidas organizadas crece, principalmente por el perfil de sus integrantes. En Rio de Janeiro, la Raça Rubro-Negra y la Torcida Jovem do Flamengo, por ejemplo, llevan la música de los bailes funks de las favelas cariocas a los estadios de fútbol. No solo cambian los ritmos entonados, también aparecen letras más ofensivas y agresivas. Hay un nuevo estilo de vida y un renovado ciclo generacional de las torcidas organizadas. Con el funk, la imagen de estos grupos pasa a ser asociada a la violencia urbana, la delincuencia juvenil y al consumo de drogas que progresivamente crece en las metrópolis brasileras.

En los últimos años, hay una nueva tendencia del Estado y los medios de comunicación de masa en relación a la violencia en los estadios. Hay una reinstitucionalización de las torcidas organizadas. La finalidad es su reincorporación al proyecto de espectacularización del deporte al ritmo de los intereses comercialpedagógicos del mercado. Al mismo tiempo, el principal canal que controla la trasmisión del campeonato, la red Globo, fomenta la aparición de nuevas torcidas que se diferencian de las torcidas organizadas de antaño. Para empezar, estos nuevos colectivos están constituidos por jóvenes de clase media que se inspiran en el modelo de barras argentinas, pero rehusando de la violencia. En otras palabras, hay un intento del Estado y los medios de "pacificar" los estadios. Para ello, por un lado, reinstitucionalizan a las torcidas organizadas jóvenes a los fines de judicializar sus violencias; y por el otro lado, fomentan y estimulan la emergencia de nuevas torcidas organizadas que están más centradas en "la fiesta" y el "color" de las tribunas que en las peleas.

En el caso mexicano, no había una asociación fuerte entre los aficionados al fútbol y la violencia hasta el surgimiento de las barras a mediados de los noventa. Antes de esto, fueron los partidos de fútbol americano universitario que generaban preocupaciones de violencia entre los aficionados. En comparación con otros casos nacionales, las rivalidades entre aficionados de fútbol de los diferentes equipos "grandes" -Chivas, América, Cruz Azul y Pumas - fueron relativamente pacíficas antes del surgimiento de las barras. Era posible portar la camiseta de alguno de estos clubes en cualquier lado, aún en el estadio rival sin recibir represalias físicas. La interacción entre los aficionados rivales consistía principalmente en bromas o apuestas. En la actualidad todavía es común que varios miembros de la misma familia o el mismo grupo de amigos sigan a diferentes equipos y que puedan portar las camisetas de sus equipos en la mayoría de los espacios públicos sin problemas.

Con el surgimiento de las barras, empezaron a ocurrir algunos enfrentamientos violentos en los alrededores de los estadios o en los barrios entre subgrupos (parecidos a las "peñas" de Costa Rica y Argentina) de barras de diferentes equipos. Sin embargo, como en el caso de Costa Rica, el propósito principal de las barras no es la violencia. Más bien los enfrentamientos violentos ocurren como un factor secundario cuando cruzan caminos. En respuesta a estos enfrentamientos, las autoridades comenzaron a mantener separadas a las barras rivales en sus llegadas y salidas de los estadios. Sin embargo, los líderes de las barras han observado que frecuentemente los policías tienen poco entrenamiento en estas actividades y se han quejado de que las autoridades no incluyen suficientemente a los líderes de las barras en la planificación de sus acciones.

A pesar del hecho de que las barras y sus integrantes generalmente quieren evitar enfrentamientos violentos con sus rivales, existe la creencia entre las autoridades, los medios de comunicación y el público en general en México, de que los barristas son violentos y una amenaza a la seguridad pública. Esta imagen de barristas violentos es frecuentemente explicada en los medios como un resultado de la "argentinización" de los aficionados mexicanos. Sin embargo, pensamos que la preocupación verdadera tiene que ver con quiénes son los barristas y dónde llevan a cabo sus actividades. Es preciso notar que el gran crecimiento de las barras involucró también lo que podríamos llamar su proletarización. Por primera vez en el futbol mexicano, grandes números de jóvenes de barrios populares comenzaron a asistir colectivamente a los estadios, en muchos casos ubicados en barrios de clase media. Esta presencia de grupos organizados de jóvenes populares, además fuera del control de instituciones como escuelas o lugares de empleo, en los estadios, en barrios de clase media y en 
las salas a través de la televisión, ha generado un tipo de pánico de inseguridad, aprovechado por los medios por su capacidad de captar la atención de audiencias y así vender.

Entre tanto, en Costa Rica, la performance estructurada del aliento mencionada por Rodríguez (2018), ha posibilitado la gestación y reproducción de conductas y acciones violentas por parte de las barras. Esta performance se pone de manifiesto en varias dinámicas o circunstancias: en la simbología barrista, la cual se relaciona con códigos masculinizados, en donde la barra contraria o la policía suponen instancias cargadas de connotaciones sexualizadas (feminizadas u homosexualizadas); en los cánticos y distintas prácticas ritualizadas como las "misiones", que son incursiones en campo enemigo para hacerse con algún bien particular (bombos, banderas, lienzos, camisetas, etcétera). Tanto los ultras, como los integrantes de las barras de La Doce y de La Garra, deben de tener cuidado de los lugares que visitan. Además, en sus trayectos a los estadios, dependiendo de los lugares que deben transitar, no visten ningún distintivo del equipo, esto para no ser identificados por rivales, lo cual sería razón suficiente para un enfrentamiento físico.

En los barrios costarricenses hay jóvenes de una y otra barra (en teoría rivales) que han mantenido una amistad desde la niñez, la cual no se borra, en lo absoluto, por esta lógica; los jóvenes en estos escenarios siguen siendo amigos, aunque pertenezcan a barras contrarias. Las barras no se estructuran para ser violentas. Ellos quieren seguir a su equipo, por eso nacieron como barra, y en los trayectos subsecuentes de esa afirmación original (el aliento a un equipo de fútbol) surgen manifestaciones consideradas por algunos sectores sociales como patológicas y violentas.

Hay un primer elemento en común que sobresale al comparar los cuatro casos: en todos ellos hay un pánico moral sobre estos colectivos. Los medios de comunicación masivos, distintos estamentos estatales y gran parte del sentido común, reducen la existencia y pertenencia de las barras o torcidas latinoamericanas a los episodios de violencia. La condena social no tiene un correlato con los niveles de violencia; es decir, en todos los países analizados hay un estigma igualmente distribuido, independientemente de la cantidad de muertos o la frecuencia de enfrentamientos que cada caso registra. Esto nos lleva a pensar que hay una visión estereotipada de estos colectivos.

La dinámica de los enfrentamientos presenta continuidades y discontinuidades. Argentina y Brasil parecen ser los países que más letalidad registran en comparación con México y Costa Rica. Además, Argentina lidera la novedad de los últimos años: el aumento exponencial de enfrentamientos entre hinchas del mismo equipo. Esto no quiere decir que en los otros países este fenómeno no exista, pero queda claro que en el país gaucho ya se ha tornado una costumbre. En todos los casos los enfrentamientos con la policía son una constante, lo que muestra que las fuerzas de seguridad no están dispuestas o preparadas para enfrentar los conflictos que involucran a las barras o torcidas organizadas.

La violencia presenta temporalidades y espacialidades disimiles. Tanto en Brasil como en Argentina, la violencia está en los comienzos de estos colectivos, sin embargo, ella explota entre los ochenta y los noventa. En México la violencia aparece recién con la llegada del nuevo milenio, como parte del surgimiento de las barras. De todas maneras, no se identifican niveles de violencia como en otros países del continente, lo cual no evita que haya una estigmatización construida mediáticamente sobre estos colectivos (lo que lleva ahablar de una "argentinización" de las barras mexicanas). En Costa Rica la violencia parece estar presente desde que nacieron las barras. La dinámica de las peleas es similar al caso argentino durante los noventa. En otras palabras, las emboscadas de Argentina son muy similares a las misiones de Costa Rica. La desmasculinización del rival es una constante. Tanto en Argentina, México y Costa Rica el “aguante”, con su apoyo incondicional al club, aparece como una categoría central para entender la legitimidad que la violencia tiene en estos grupos.

Para finalizar este eje, hay una última conclusión que extraemos del ejercicio comparativo: no hay una relación mecánica o de reflejo entre la violencia social de un país y la violencia reinante en su fútbol. Si tomamos a las tasas de homicidios por cada cien mil habitantes de cada país como un indicador de su violencia social, encontramos la siguiente distribución decreciente: Brasil 26.54; México 16.3; Costa Rica 12; Argentina $6{ }^{4}$. Si bien no contamos con estadísticas oficiales sobre las muertes vinculadas a espectáculos 
futbolísticos, nuestras investigaciones indican que Argentina y Brasil cuentan con algunas centenas de víctimas fatales mientras que la estadística acumulada de Costa Rica y México no llegan a las dos cifras. Lo que queremos decir es que nada indica que una sociedad violenta, como la situación mexicana actual, lleve necesariamente a un fútbol violento. Queda a las claras que entre la violencia social y la violencia en el fútbol existe una relación de autonomía relativa, es decir, hay condicionamientos más no determinación.

\section{Conclusiones}

El desafío propuesto en este artículo fue contribuir a superar los enfoques nacionales aislados, que no tienen en cuenta la internacionalización de los hinchas en el mundo contemporáneo, sus formas de circulación, comunicación e intercambio. Ante esta motivación inicial, la propuesta aquí presentada consistió en integrar los análisis de casos nacionales, para extender su alcance y obtener elementos comparativos capaces de ir más allá de las especificidades locales. Para hacer eco de las palabras del historiador escocés Robert Frank, especialista en historia de las relaciones internacionales: "ya hace mucho tiempo que sabemos que debemos salir del marco nacional" (Moreli, 2017, p. 6).

Se sabe que en Europa una serie de investigaciones se han dedicado, durante las últimas décadas, a matizar y a revisar versiones del hooliganismo, ya sean las perspectivas sociológicas eliasianas (Giulianotti, Bonney y Hepworth, coords., 1994; Armstrong, 1998), o aquellas que la entienden como manifestación exclusivamente británica (Dunning, Murphy y Williams, coords., 2001). En América Latina, estudios sobre barras, hinchadas e torcidas organizadas han sido desarrollados desde los años 1990 (Murad, 1996; Toledo, 1996; Alabarces et al., 2005), pero son menos frecuentes las investigaciones que mapean los comportamientos de los grupos de aficionados adscriptos a clubes de fútbol a partir de una observación regional más amplia (Garriga Zucal, 2015; Hollanda y Rodríguez, 2017; Cabrera et al., 2014). Con ese objetivo, hemos tratado de estructurar una comparación en base a tres ejes analíticos.

El primero abarcó las temporalidades propias del desarrollo de cada sociedad, con el fin de mostrar cómo estas posibilitan el entendimiento de determinadas constantes, por ejemplo, las relaciones entre los liderazgos de las hinchadas y la dirección de los clubes a los que se vinculan. Primero en Argentina y Brasil, y un par de décadas después en Costa Rica y México, se observa un sentido de autonomía y alejamiento del universo clubístico, donde prevalecen las relaciones personales, de tutela y dependencia entre las dos entidades. Aunque se verifique una tendencia de progresiva autonomización de las agremiaciones de hinchas, con el culto a símbolos e identidades propias, la relación con el club es una posibilidad que siempre se coloca en el horizonte, en medio de un juego tenso de disputas y negociaciones políticas.

Otra constante que se observó en todos los países fue el crecimiento de las barras y simultáneamente su estigmatización dentro y fuera del universo del fútbol. Mientras las ligas profesionales, los clubes y sus patrocinadores buscaban extender el consumo del fútbol como mercancía a las clases populares, la opinión pública, los gestores y el aparato represivo policial tendían a estigmatizar a las hinchadas como potencialmente violentas y amenazadoras. Las hinchadas no respondieron a esta estigmatización pasivamente y se estableció así un círculo vicioso de profundización recíproca de la oposición entre las hinchadas y vastos sectores de la sociedad. La incomprensión mutua lleva a la ausencia de diálogo y a la invisibilización de los canales de mediación de conflicto, aumentando la predisposición para los combates entre las hinchadas rivales, así como entre estas y la policía.

El segundo eje enfatizó en las estructuras internas de poder de las asociaciones de hinchas, con la identificación de un crecimiento exponencial del número de adeptos de las hinchadas y la expansión de su radio territorial en el espacio urbano de las grandes ciudades como Buenos Aires, Ciudad de México, San José, Río de Janeiro y São Paulo. Se trató de mostrar la manera en que tal expansión ha llevado a la necesidad de reestructurar las formas de comando y de poder interno. Como efecto de la segmentación espacial, los personajes que ocupan la dirección/control de los grupos, muchos de ellos por su carisma y 
ascensión generacional, pasan a convivir con sublíderes más jóvenes que surgen de las localidades de origen de los hinchas, en un escenario dinámico de creciente fragmentación, de rediseño organizacional y de dispersión centrípeta de las formas centralizadas de control político.

Aunque el estadio sea el punto de reunión y de cohesión de los diversos subgrupos provenientes de zonas geográficas distintas, momento en que el desempeño colectivo del aliento congrega a las hinchadas, se verificó una dinámica de rechazo a someterse a las autoridades de los líderes. Se trata de una "ideología" grupal e individual que no se somete a las jerarquías, que va en contra de la estructura piramidal de los grupos y que evita condicionar sus comportamientos a la burocracia, incluso a la de los grupos con que se identifican, constituyendo formas innovadoras para la exaltación y la práctica del libre arbitrio y de la libertad.

El tercer eje del artículo versó sobre el tema más problemático asociado a las prácticas de las hinchadas: la violencia. Se ha señalado que la palabra se utiliza de manera reductora y estigmatizante por los medios de comunicación, sin la debida cualificación conceptual. La utilización generalizada se emplea para referirse a una dimensión a la vez material y simbólica, espontánea y premeditada, activa y reactiva, objetiva y subjetiva, sin observar las categorías nativas, con sus respectivos sentidos y significados intrínsecos. Esto impide la diferenciación del rol de los actores, así como de las "armas" y de las reglas creadas y establecidas desde las mismas hinchadas. Así, en general, cuando los medios de comunicación, las autoridades y otros sectores sociales discuten el fenómeno de la violencia en el fútbol silencian su propio involucramiento, generalizan los términos del debate, refuerzan los estereotipos y naturalizan comportamientos que son, en realidad, de alcance social y cultural.

Los intentos de pacificar los estadios, proyecto acorde con las premisas mercantiles del fútbol de la espectacularización y mediatización (Kennedy y Kennedy, 2016), encuentran así reelaboraciones de códigos y dinámicas de resistencia, con nuevos registros de conflicto entre hinchadas y policías, hinchas de distintos clubes, o incluso entre hinchas de la misma agremiación clubística. La lógica de las grandes hostilidades entre hinchadas de clubes oponentes sigue manifestándose, pero se desplaza hacia afuera de los estadios. En lugares menos previstos, la intensidad de los enfrentamientos, por lo menos en tres de los cuatro casos analizados, asiste a una radicalización aún mayor, con peleas colectivas seguidas, en casos extremos, de muertes y de uso de armas de fuego, como ocurre con alguna recurrencia en la Argentina y en el Brasil del siglo XXI.

Con base en los tres ejes anteriormente descritos, el presente artículo intentó reunir estudios de especialistas hasta hoy abordados por separado, según las particularidades características de cada país. Con tal integración, el texto trató de dar a conocer una realidad compleja y multifacética, que dialoga no solo con las transformaciones del fútbol profesional en la contemporaneidad, sino también con las vicisitudes sociales, políticas y culturales del medio circundante.

En este texto hemos señalado algunas variaciones importantes entre los cuatro casos nacionales. Posiblemente el resultado más llamativo de este ejercicio comparativo fue la constante visualización de las barras como focos de enfrentamientos entre el Estado y las élites, por un lado, versus integrantes masculinos de las clases populares, por el otro. La mayoría de las transformaciones, las formas organizacionales y los conflictos violentos que hemos descrito son relacionados con este hecho. Nos parece importante desnaturalizar este posicionamiento de las barras como focos de enfrentamiento y replantearlo como resultado de procesos históricos ampliamente difundidos en América Latina, pero no irreversibles.

\section{ReFERENCIAS}

Alabarces, P. et al. (2005). Hinchadas. Buenos Aires: Prometeo.

Armstrong, G. (1998). Football Hooligans: Knowing the Score. Oxford: Berg.

Cabrera, N. (2018). Violencia, estigma y desplazamientos: la reconfiguración social y moral de Los Piratas en clave procesual. Revista de Antropología y Arqueología. 30, 129-150. 
Cabrera, N., Fadori Soares, M. y Schwartz, G. (2014). Apuntes para un estudio comparativo entre hinchadas y torcidas organizadas. Revista Movimento, 20 (nesp. “Sociologia Pública do Esporte nas Américas”), 163-176.

Dunning, E., Murphy, P. y Williams, J. (coords.) Fighting Fans: Football Hooliganism as a World Phenomenon. Dublin: University College Dublin Press.

Frydenberg, J. (2011). Historia social del fútbol: del amateurismo a la profesionalización. Buenos Aires: Siglo Veintiuno Editores.

Garriga Zucal, J. (2014). Haciendo amigos a las piñas: violencia y redes sociales de una hinchada de fútbol. Buenos Aires: Prometeo Libros.

Garriga Zucal, J. (2015). El inadmisible encanto de la violencia: policías y barras en una comparación antropológica. Buenos Aires: Cazador de tormentas.

Garriga Zucal, J. (coord.). Violencia en el fútbol: investigaciones sociales y fracasos politicos. Buenos Aires: Ediciones Godot.

Giulianotti, R., Bonney, N. y Hepworth, M. (coords.) Football, violence and social identity. London: Routledge.

Hall, S.et al (1978). Policing the Crisis: Mugging, the State, and Law and Order. Londres: Macmillan Press.

Hollanda, B.B., Rodríguez, O.(coords.) (2017). Torcidas organizadas na América Latina: estudos contemporâneos. Rio de Janeiro: 7 Letras.

Kennedy, P. y Kennedy, D. (2016). Football in Neo-liberal Times: A Marxist Perspective on the European Football Industry. London: Routledge.

Magazine, R. (2008). Azul y oro como mi corazón: masculinidad, juventud y poder en una porra de los Pumas de la UNAM. Ciudad de México: Afínita; Universidad Iberoamericana.

Moreira, M.V. (2008). Buenos luchadores y grandes hombres: poder y política de una hinchada de fútbol en Argentina. Questión, 1 (17).

Moreli, A. (2017). Vida (e morte?) da história global. Revista Estudos Históricos. 30 (60), 5-16.

Murad, M. (1996). Dos pés à cabeça: elementos básicos de sociologia do futebol. Rio de Janeiro: Irradiação Cultural.

Silva, E. M. da. (1996). As torcidas organizadas de futebol: violência e espetáculo nos estádios. São Paulo: Dissertação de Mestrado, PUC-SP.

Toledo, L. H. de (1996). Torcidas organizadas de futebol. Campinas: Autores Associados.

Rodríguez, O. (2006). Entre cánticos y graderias: la construcción de un colectivo juvenil del ámbito futbolístico en Costa Rica. El caso de La Ultra Morada (Tesis de maestría), Universidad de Costa Rica, San José.

Rodríguez, O. (2014a) De sur a norte: barrio y clase en la Ultra Morada. Revista Reflexiones, 93, volumen 1, 9-18.

Rodríguez, O. (2014b). Poder y conflicto en una barra de fútbol: el caso de la Ultra Morada. Esporte e sociedade. 9 (24), $1-20$.

Rodríguez, O. (2018). La 'previa' y la salida’: ¿prácticas rituales en La Ultra Morada?, En prensa,1-18.

Elias, N. (1993). Elproceso de la civilización. Investigaciones sociogenéticas y psicogenéticas. Fondo de Cultura Económica, Buenos Aires.

Varela Hernández, S. (2012). Al América se le odia o se le ama: afición futbolera, melodrama, aguante, identidad y clientelismo en México (Tesis de doctorado), Universidad Iberoamericana, Ciudad de México.

\section{Notas}

1 En 1955 un movimiento cívico-militar derrocó al entonces presidente Juan Domingo Perón. El proceso, autodenominado "Revolución Libertadora”, se proponía “desperonizar” la sociedad argentina. La persecución ideológica y la proscripción electoral del peronismo duró hasta 1973.

2 Esta categoría ha sido estudiada, principalmente, en Argentina (véase, por ejemplo, Garriga, 2014 y 2015; Moreira, 2008). En el caso brasileño, aunque se observen influencias de aquel país en sus "torcidas", la categoría aguanteno está presente en el universo de los hinchas de Brasil. 
3 Conjunto de prácticas estructuradas/organizadas o no, ritualizadas y simbolizadas, relacionadas con la puesta en escena de las barras, pero también con todo lo que implica la escenificación (organización, mando, espectacularización, etcétera). Para una mejor comprensión de este performance estructurado del aliento, ver Rodríguez (2018).

4 Datos de la Oficina de Naciones Unidas contra la Droga y el Delito, año 2012. 